\title{
Pesticide makes invading ants suicidally aggressive
}

Neonicotinoids change behaviour in ways that could affect spread of invasive species.

\section{Brian Owens}

23 October 2013

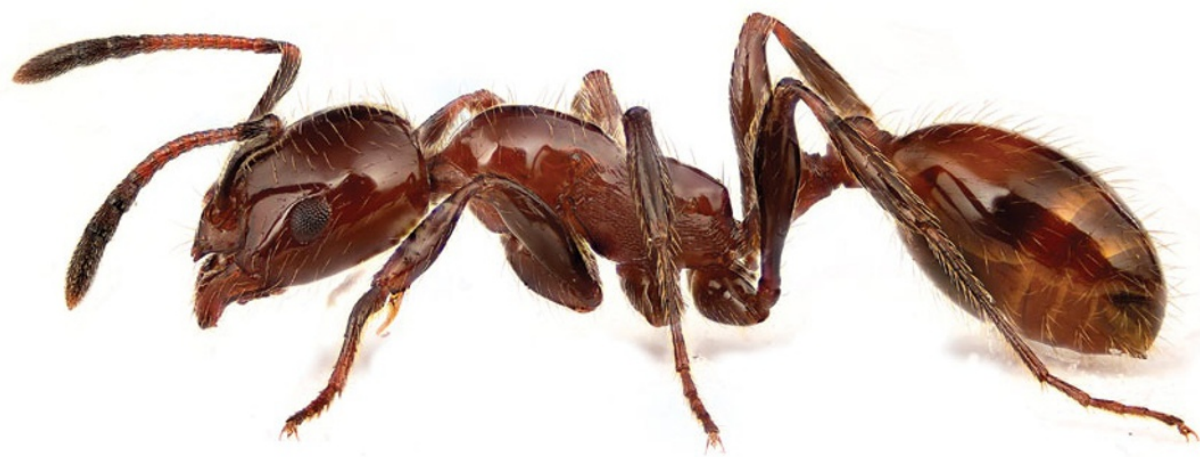

George Novak

The southern ant of New Zealand is facing increasingly aggressive Argentine ants, an invasive species, possibly an effect of insecticides in the environment.

Neonicotinoid insecticides have developed a bad reputation for their unintended and potentially harmful effects on pollinating insects such as bees. A study in New Zealand now shows that the chemical can also change how native and invasive ants interact.

New Zealand is facing an invasion of Argentine ants (Linepithema humile), which compete with native southern ants (Monomorium antarcticum). The insects often meet in urban or agricultural areas, where neonicotinoids are in use. So ecologist Rafael Barbieri, a graduate student in the lab of Philip Lester at Victoria University of Wellington, wondered whether the behavioural changes that have been associated with sublethal neonicotinoid exposure in other insects affect how the two species interact.

"Any changes in behaviour could potentially affect the structure of the entire community," he says.

As the team describes in Proceedings of the Royal Society $B^{1}$, Barbieri exposed the ants to extremely low doses of a common neonicotinoid and examined how the insecticide affected each species' behaviour. He did not observe an effect on the foraging behaviour or survivability of either species in isolation, although they did cut the brood size of the invasive Argentine ant in half. But it was when the two species met that the real effects were seen.

\section{Fight, fight, fight}

When the southern ant was exposed to the potent neurotoxins, it became much less aggressive towards the invader. This increased the survival odds of the Argentine ant, and could help it to spread. However, when invasive ants were exposed to the insecticides, they became much more aggressive towards unexposed Southern ants — so aggressive, in fact, that they risked their own lives to attack. As a result, unexposed natives were able to completely eradicate their exposed rivals.

The mixed results make it difficult to predict whether, and how, neonicotinoids will exacerbate the invasion of Argentine ants, says Scott Black, executive director of the Xerces Society for Invertebrate Conservation in Portland, Oregon. But it is another example of how low levels of these insecticides can change behaviour in many different kinds of insects. "It adds to the growing body of literature that raises concerns over the expanding overuse of these insecticides," says Black. "We need to find where and how they can be safely used."

Barbieri agrees that the biggest problem with neonicotinoids, and indeed any pesticides, is what he calls "reckless use". But he suggests that the chemicals could be used to counter the Argentine ant invasion. Because they reduced the invaders' brood size, and 
made the invaders less likely to survive against unexposed natives, a judicious use of neonicotinoids could be an effective way of controlling the spread of the Argentine ant. "There's no doubt that neonicotinoids are fantastic to control insect pests," says Barbieri. "But we should be more careful in the way we use them in nature."

Nature | doi:10.1038/nature.2013.14003

\section{References}

1. Barbieri, R. F., Lester, P. J., Miller, A. S. \& Ryan, K. G. Proc. R. Soc. B http://dx.doi.org/10.1098/rspb.2013.2157 (2013). 